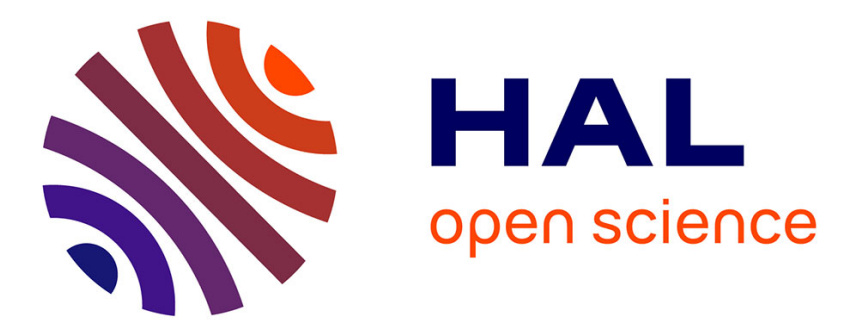

\title{
The Role of Contemporary Skills in Information Technology Professionals: An FsQCA Approach
}

Michail N. Giannakos, Ilias O. Pappas, Patrick Mikalef

\section{To cite this version:}

Michail N. Giannakos, Ilias O. Pappas, Patrick Mikalef. The Role of Contemporary Skills in Information Technology Professionals: An FsQCA Approach. 16th Conference on e-Business, e-Services and e-Society (I3E), Nov 2017, Delhi, India. pp.485-496, 10.1007/978-3-319-68557-1_43 . hal-01768510

\section{HAL Id: hal-01768510 \\ https://inria.hal.science/hal-01768510}

Submitted on 17 Apr 2018

HAL is a multi-disciplinary open access archive for the deposit and dissemination of scientific research documents, whether they are published or not. The documents may come from teaching and research institutions in France or abroad, or from public or private research centers.
L'archive ouverte pluridisciplinaire HAL, est destinée au dépôt et à la diffusion de documents scientifiques de niveau recherche, publiés ou non, émanant des établissements d'enseignement et de recherche français ou étrangers, des laboratoires publics ou privés. 


\title{
The Role of Contemporary Skills in Information Technology Professionals: An FsQCA Approach
}

\author{
Michail N. Giannakos, Ilias O. Pappas and Patrick Mikalef \\ Norwegian University of Science and Technology, Trondheim, Norway \\ michailg@ntnu.no
}

\begin{abstract}
Information Technology (IT) industries' knowledge and ability to innovate, heavily relies in the skills of the IT professionals. In particular, inefficiencies usually come from the lack of skills or IT professionals' inability to apply them in a way that allows a firm to adapt and evolve concurrently with business demands. In order to examine the interplay of skills related with data analysis, entrepreneurship, business, communication and collaboration, and their combined effect in enhancing employees' perceived work performance, a conceptual model is developed and examined on a data sample of 72 IT professionals, through fuzzy-set qualitative comparative analysis (fsQCA). The findings indicate five configurations that lead to high perceived work performance. The outcomes of the analysis show the importance of collaboration and entrepreneurship, since they appear in most of the configurations/solutions; but also the importance of data analysis, which can lead to high work performance even with the absence of all the other skills. This study also confirms that the identified skills portray to a good extend IT professionals' work performance, which is critical for a firm to evolve and innovate.
\end{abstract}

Keywords: data analytics skills, entrepreneurial skills, business skills, communication skills, collaboration skills, work performance, IT professionals

\section{Introduction}

IT firms' performance and competitiveness depends to a great extent on IT professionals' knowledge and expertise towards the software development process [28] as well as their non-technical skills (e.g., management, communication) [7]. Prior research guides how to manage the organizations [10], and highlights the importance of both technical and non-technical skills and competences [7,22]. Related work however do not incorporate skill related with the $21^{\text {st }}$ century technological developments [35], like understanding/analyzing big data and entrepreneurship amongst others [1,3,23]. Despite the fact that those technological developments provide a way forward for solving the global challenges of the $21^{\text {st }}$ century, building sustainable development, and advancing human welfare [35], it is still unclear how those skills might benefit IT professionals' evolvement and performance.

IT professional's performance has been investigated considering different skills, however, mainly, without studying the existence of different combinations among these 
skills, which may lead to different models explaining IT professionals performance. Such approaches (e.g., multiple regression analysis, structural equation modelling) assume that relations among the variables are symmetric and offer one single best solution explaining the outcome. This may be misleading as within a sample the variables may also have asymmetric relationships, not identifiable by variance based approaches [36]. Multiple configurations of the examined skills that lead to multiple solutions, explaining the same result, representing a larger part of the sample, need to be identified. This paper complements prior work by utilize multiple configurations to explain how various skills might combine to result high work performance of IT professionals.

This exploratory study draws data from 72 IT professionals, to better understand how selected important skills (namely: data analytics, entrepreneurial, collaborative, communication and business skills) influence perceived work performance. Thus, we build on complexity theory and configuration theory and employ the novel fuzzy-set Qualitative Comparative Analysis (fsQCA) [5] in order to identify multiple solutions of the various skills that result high work performance of the IT professionals. FsQCA is appropriate for explaining the complex interrelations among variables, as their combinations and interdependencies lead to the desired outcome and is suitable because it may offer valid responses in studies with small samples [5]. FsQCA has received increased attention in different areas, such as business [20], learning analytics [18] and others, and we build and expand on their contributions. The paper contributes to the literature first, by offering empirical evidence on the important role of data analytics, communication, collaborative, entrepreneurial and business skills on the development of IT professionals performance in today's demanding and continuously evolving IT firms; through the lens of the fsQCA approach.

The rest of the paper is structured as follows. In the next section we present the background and related work upon which the conceptual model is built. In section 3 the methodology is outlined, and in section 4 the findings of the study are presented. In closing, section 5 provides a discussion on research directions and areas of future interest.

\section{Background and conceptual model}

In today's IT industry, hard skills, like software development, architecture, testing and maintenance are essential for professionals to take on an entrepreneurial role and focus on innovation. However, the complete spectrum of needed skills for IT professionals is determined by the tasks that are required in their work environment [12], and as the complexity of technology increases, the skills of related professionals must also increase and evolve [37]. Thus, in addition to hard skills, $21^{\text {st }}$ century IT professionals must pose a robust understanding of skills related to data understanding and analysis [9], entrepreneurship and business as well as communication and collaboration with other professionals but also the end users [22]. These skills allow them to utilize resources and, understand needs and opportunities in order to gain innovative outcomes and competitive advantages. Today's challenges of IT industry faced by IT professionals go beyond solving technical problems and the expected skillset requires knowledge 
in relation to business functionality, decision making strategy and evolving environment, especially in an increasingly turbulent business and technological context [37].

Kim et al. [8] describe IT expertise skills as "professional skills and knowledge of technologies, technology management, business functions, and relational (or interpersonal) areas necessary for IT staff to undertake assigned tasks effectively" (p. 492). Related work in the area of technical skills and abilities (hard skills) of IT professionals based on their training and expertise in specific technical areas, and these skills can advance the development or configuration of IT-related services [4]. In order to develop IT-applications that satisfy today's increased demands, IT professionals must have the abilities to communicate with the end user and understand the tasks of other functions in addition to their technical skills [34]. In this study, we combine data analytics, entrepreneurship, business, collaboration and communication to offer an empirical evidence about the critical role of those emerging skills in IT professionals' work performance, and ultimately in the IT industry as a whole.

To address this gap, we examine IT professionals' perceived work performance (we hereinafter refer to it as work performance) by unravelling configurations of causally related sets of the five aforementioned skills. Relationships between two skills (e.g., X, $\mathrm{Y})$ are complex, and the presence of one (X) may lead to the presence of the other (Y), indicating sufficiency. Also, skill Y may be present even with skill $\mathrm{X}$ being absent, thus the presence of $\mathrm{X}$ is a sufficient but unnecessary condition for $\mathrm{Y}$ to occur. With the presence of additional factors, $\mathrm{X}$ may be necessary but insufficient for $\mathrm{Y}$ to occur. We posit that there is a synergy between the five skills in explaining work performance of IT professionals. We theorize that there is not one single, optimal, configuration of such skills. Instead, multiple and equally effective configurations of causal conditions exist, which may include different combinations these skills. Depending on how they combine they may or may not explain IT professionals high work performance. 


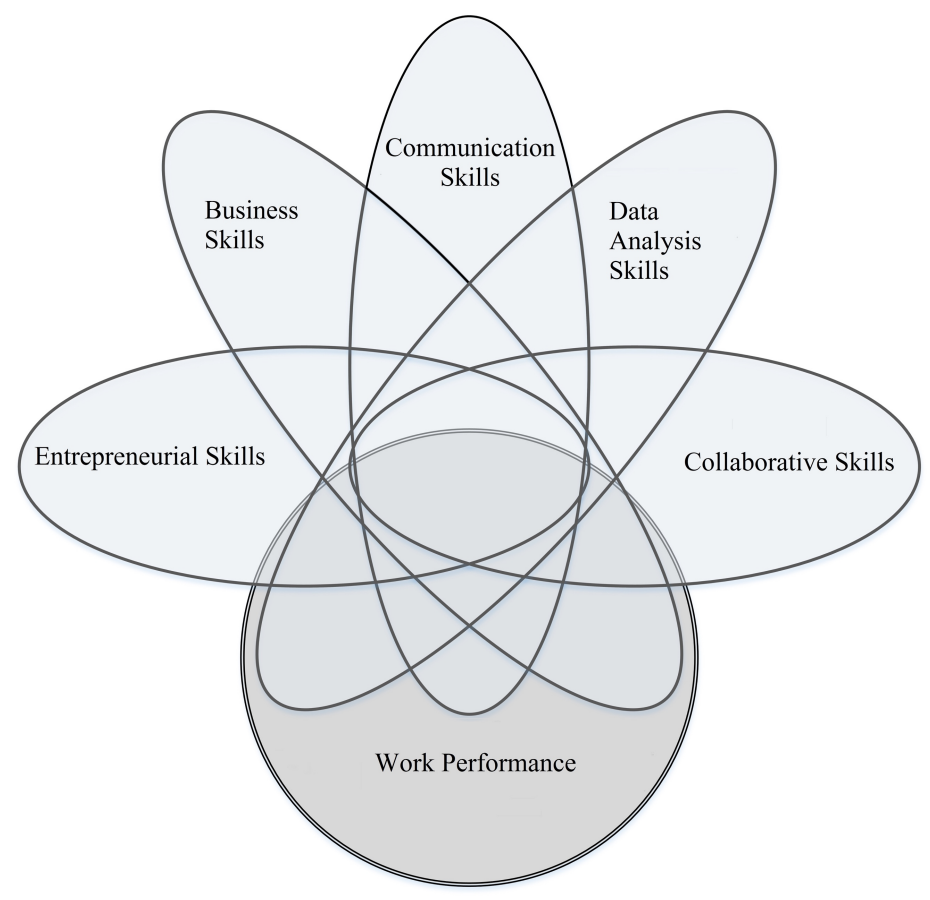

Fig. 1. Venn diagram illustrating the conceptual model explaining work performance

To conceptualize these relationships, we propose a theoretical model (Figure 1) illustrating six constructs (five types of skills and work performance) and their intersections. The overlapped areas represent possible combinations among factors, that is areas that one factor may exist together with the rest (e.g., combinations that explain high purchase intentions are included within the outcome of interest area).

Drawing on complexity theory and the principle of equifinality, a result may be equally explained by alternative sets of causal conditions [5]. These conditions may be combined in sufficient configurations to explain the outcome [36]. IT-related skills, especially the skills possessed by the IT professionals, can be viewed as complimentary to each other. If IT personnel have adequate set of skills, they can combine those skills to develop, improve or adjust IT applications efficiently and effectively in order to increase the quality and innovation of the produced products and services $[30,33]$. Demands from the IT industry indicates the need for various sets of skills; for instance, drawing from both IT personnel job advertisements but also the guidelines for IT curriculum design [29, 31]. For example, after analyzing job advertisements for IT professionals (e.g., software engineers) across two decades; it became clear that business skills, if one of the most important knowledge areas for hiring IT personnel [34]. Along the same lines, IT curriculum guidelines - developed by the Association for Computing Machinery (ACM), the Association for Information Systems (AIS) and the IEEEComputer Society $[29,31]$ - suggested that IT professionals should be equipped with: business skills and business domain fundamentals. Business skills and business domain 
fundamentals includes leadership, collaboration and communication skills as well as knowledge and skills regarding general business models, key business specializations, and the evaluation of business performance [34]. Thus, high work performance may be achieved in more than one combination of skills in the IT industry and therefore configuration theory and fsQCA approach are essential in the realization of our research.

Configuration theory proposes the principle of causal asymmetry, which means that, for an outcome to occur, the presence and absence of a causal condition depends on how this condition combines with the other conditions [5]. Also, causal asymmetry suggests that the causal conditions that explain the presence of an outcome, cannot be assumed as mirror pictures of conditions explaining the absence of the same outcome [5]. For instance, alternative configurations of high work performance in IT professionals may include high data analysis skills in one configuration and low communication skills in a different configuration. Thus, the same outcome may be influenced either positively or negatively by a specific factor, depending on how it combines with the other factors. Furthermore, high data analysis skills might be part of a combination that explains high work performance, and might also be part of another combination that explains medium work performance (in this study we focus only in high work performance). Thus, configurations that explain the presence of an outcome do not suggest that their reverses are also able to explain the absence of the same outcome.

\section{$3 \quad$ Research Methodology}

\subsection{Sampling}

To actualize the objectives of this study a custom-built questionnaire was developed and sent to respondents to fill out electronically (online questionnaire). Our target population consisted of IT graduates from Norway's primary university for technological education, with respondents filling out the questionnaire required to be in an active IT position. The survey was conducted between February and March 2016. In order to recruit participants, we distributed the online survey via the IT graduates' alumni mailing list. A raffle was created with gift cards as a reward to the participants. In total, 72 responses were gathered.

The sample consists of 63 men (87.5\%) and 9 women (12.5\%), with relatively long experience in the IT industry, which range from 2 to 33 years with an average of 13.21 years (S.D.: 7.35 years). Although the participants of the study had formal IT education and hold IT positions, there is a variation in their expertise and job titles; in particular, 16 are developers (e.g., software engineer, mobile developer), 6 directors (e.g., CTOs, strategy directors, business development), 14 project managers, 21 IT consultants, 8 software architects, 3 in R\&D positions and 5 with responsibilities in various stages. The majority of firms operated in the IT sector (54.2\%), with companies from oil and gas $(9.7 \%)$ and telecommunications $(9.7 \%)$ following, there was also a small proportion of firms from utilities, consumer goods and healthcare (approx. 3-5\% from each sector). The vast majority (59.7\%) belonged to SME size-class (1-249 employees), with $40.3 \%$ being large enterprises (250+ employees). More specifically, from the SME grouping, 
micro firms (0-9 employees) accounted for 15,3\%, small firms (10-49 employees) for $23,6 \%$, and medium-sized (50-249 employees) firms for $20,8 \%$. The majority of the firms were active in the national level $(91.7 \%)$ with most of them being also active in the inter-national arena $(65.3 \%)$.

\subsection{Measures}

The questionnaire comprised of three parts. First the respondents were presented with different questions about their demographics and personal work experience, followed by the second part which included questions in relation to the size, orientation and focus of their firm, the third part included measures of the constructs related with their Data Analysis Skills (DAS), Entrepreneurial Skills (ES), Business Skills (BS), Communication Skills (ComS), Collaborative Skills (ColS) and Work Performance (WP) as those were identified in the literature. The survey included scales for all the constructs that were used in this study with a seven-point Likert-type scale. The operational definitions of all constructs are presented in table 1, along with their source in the literature.

Table 1. Operational Definitions of the Constructs

\begin{tabular}{|l|l|c|}
\hline \multicolumn{1}{|c|}{ Construct } & \multicolumn{1}{|c|}{ Operational Definition } & Source \\
\hline $\begin{array}{l}\text { Data Analysis } \\
\text { Skills (DAS) }\end{array}$ & $\begin{array}{l}\text { DAS is the degree to someone's capacity to make sense, extract } \\
\text { intelligence and make decisions from big data. }\end{array}$ & {$[32]$} \\
\hline $\begin{array}{l}\text { Entrepreneurial } \\
\text { Skills (ES) }\end{array}$ & $\begin{array}{l}\text { ES indicates how confident respondents are in their possession of } \\
\text { a high-enough level of certain skills related to entrepreneurship } \\
\text { (e.g., feel capable to start a firm, higher personal attraction). }\end{array}$ & {$[13]$} \\
\hline $\begin{array}{l}\text { Business Skills } \\
\text { (BS) }\end{array}$ & $\begin{array}{l}\text { BS is the degree to someone's capacity to understand business } \\
\text { functions, problems, needs, policies and plans. }\end{array}$ & {$[2]$} \\
\hline $\begin{array}{l}\text { Communication } \\
\text { Skills (ComS) }\end{array}$ & $\begin{array}{l}\text { ComS is the degree to someone's capacity to listen, communicate } \\
\text { and present ideas in a clear and concise manner }\end{array}$ & {$[13]$} \\
\hline $\begin{array}{l}\text { Collaborative } \\
\text { Skills (ColS) }\end{array}$ & $\begin{array}{l}\text { ColS is the degree is the degree to someone's capacity work and } \\
\text { coordinate group problem solving activities and utilize the proper } \\
\text { degree and type of participation. }\end{array}$ & {$[2]$} \\
\hline $\begin{array}{l}\text { Work Performance } \\
\text { (WP) }\end{array}$ & $\begin{array}{l}\text { WP is the degree to which employees are indicating their perfor- } \\
\text { mance. }\end{array}$ & {$[11]$} \\
\hline
\end{tabular}




\subsection{Data Analysis}

The constructs of this study were evaluated in terms of their reliability and validity. Reliability testing, based on Composite Reliability and Cronbach alpha, showed acceptable indices of internal consistency in that all constructs exceeded the cut-off threshold of 0.70 . For validity, the average variance extracted (AVE) should be higher than .50 , and the correlations among the variables in the confirmatory model should not exceed .8 points, the latter because exceeding 0.8 suggests low discrimination. The square root of each factor's AVE needs to be greater than its correlations with the other factors [6]. The AVEs for all constructs ranged between 0.55 and 0.80 , all correlations were lower than 0.80 , and the square root AVEs for all constructs were larger than their correlations. Next, we tested for multicollinearity [16] along with the potential common method bias by utilizing Harman's single-factor test. The variance inflation factor for each variable was under 3, suggesting multicollinearity is not an issue. Findings indicate an absence of common method bias as the first factor did not account for the majority of the variance and no single factor occurred from the factor analysis.

\subsection{FsQCA}

To address its objective this study employs fsQCA using fs/QCA 2.5 [24], which was developed through the integration of fuzzy sets and fuzzy logic principles with Qualitative Comparative Analysis (QCA) [25]. By using fsQCA researchers go beyond traditional regression based analyses, as they identify multiple pathways that explain the same outcome [27]. These pathways or combinations include variables that are not identified by regression based analyses because they influence the outcome only for a small number of cases. The aforementioned combinations create to multiple solutions, offered by fsQCA, and each variable (or condition) may be present or absent on a solution, or it may be on a "do not care" situation. The "do not care" situation indicates that the variable may either be present or absent and it does not play a role on a specific configuration [5].

\section{Data calibration}

The next step is to calibrate all factors into fuzzy sets with values ranging from 0 to 1 [28]. This procedure may be direct or indirect. In the direct, the researcher chooses three qualitative breakpoints, while in the indirect, the factors should be rescaled based on qualitative assessments. Either method may be chosen depending on data and the underlying theory [28]. The direct method of setting three values that correspond to full-set membership, full-set non-membership and intermediate-set membership is recommended [28].

Data calibration here was done based on the direct method. Since our data is skewed to the right, choosing the three qualitative anchors for the calibration based on the survey scale (seven-point Likert scale) [17, 20] would not lead to meaningful results [21]. Thus, data calibration is done by using percentiles, that is the $80^{\text {th }}$ percentile is the full- 
set membership, the $20^{\text {th }}$ percentile is the full-set non-membership, and the $50^{\text {th }}$ percentile is the intermediate set membership. Next, the values of each variable are calibrated on a linear function to fit into the three aforementioned breakpoints.

\section{Truth table analysis}

Next, fsQCA produces a truth table of $2 \mathrm{k}$ rows, on which $\mathrm{k}$ represents the number of outcome predictors and each row represents every possible combination. The truth table should be sorted based on frequency and consistency [20, 27]. Frequency describes the number of observations for each possible combination, and consistency refers to "the degree to which cases correspond to the set-theoretic relationships expressed in a solution" [5]. A frequency threshold should be set to ensure that a minimum number of empirical observations is acquired for the assessment of the relationships. For samples larger than 150 cases the threshold should be set at 3 , while for smaller samples the threshold may be set at 2 [26], thus all observations with smaller frequency are removed from further analysis. Also, the threshold for consistency is set at .80, higher than the recommended threshold of 0.75 [27]. Observations above the consistency threshold are the ones that fully explain the outcome.

\section{$4 \quad$ Findings}

The findings from the fsQCA on the configurations for high work performance of IT professionals is presented in Table 2. Every possible combination in the solution is able to explain the same outcome at a specific amount. In detail, the presence of a condition is depicted by black circles $(\bullet)$, while its absence by crossed-out circles $\left({ }^{\otimes}\right)$ [5]. The blank spaces indicate a "do not care" situation, meaning that the causal condition may either be present or absent. FsQCA identifies both core and peripheral elements, core conditions are represented with large circles, and peripheral ones with small circles. Table 2 also presents consistency values for every configuration as well as for the overall solution. All values are above the recommended threshold $(>0.75)$. Consistency measures the degree to which a subset relationship has been approximated, while coverage assesses the empirical relevance of a consistent subset [27]. The overall consistency is similar to the correlation. The overall solution coverage indicates the extent to which high work performance of IT professionals may be determined from the existing configurations, and is comparable to the R-square value reported in traditional regression analyses. The overall solution coverage of .96 indicates that a substantial amount of the outcome is explained by the five solutions. FsQCA estimates also the empirical relevance for every solution, by calculating raw and unique coverage. The raw coverage describes the amount of the outcome that is explained by a certain alternative solution, while the unique coverage describes the amount of the outcome that is exclusively explained by a certain alternative solution. The solutions presented in Table 2 explain a great number of IT professionals perceived work performance, ranging from $19 \%$ to $39 \%$ cases associated with the outcome. 
Table 2. Combinations that lead to high work performance

\begin{tabular}{|c|c|c|c|c|c|}
\hline & \multicolumn{5}{|c|}{ Solution } \\
\hline Configuration & 1 & 2 & 3 & 4 & 5 \\
\hline \multicolumn{6}{|l|}{ Skills } \\
\hline Entrepreneurial & O & & O & O & $\otimes$ \\
\hline Business & & $\otimes$ & $\otimes$ & $\bullet$ & $\otimes$ \\
\hline Communication & & $\otimes$ & $\otimes$ & - & $\otimes$ \\
\hline Collaborative & (0) & O & & O & $\otimes$ \\
\hline Data Analysis & $\otimes$ & $\otimes$ & $\otimes$ & & O \\
\hline Consistency & 0.98 & 0.96 & 0.96 & 0.99 & 0.98 \\
\hline Raw Coverage & 0.39 & 0.29 & 0.34 & 0.32 & 0.19 \\
\hline Unique Coverage & 0.06 & 0.03 & 0.07 & 0.09 & 0.03 \\
\hline \multicolumn{3}{|l|}{ Overall Solution Consistency } & \multicolumn{3}{|l|}{0.63} \\
\hline \multicolumn{3}{|l|}{ Overall Solution Coverage } & \multicolumn{3}{|c|}{0.96} \\
\hline \multicolumn{6}{|c|}{$\begin{array}{l}\text { Note: Black circles }(\Theta) \text { indicate the presence of a condition, and circles with " } x \text { " }(\otimes) \text { indicate } \\
\text { its absence. Large circles indicate core conditions, and small ones represent peripheral condi- } \\
\text { tions. Blank spaces indicate "don't care." }\end{array}$} \\
\hline
\end{tabular}

For high work performance, the five solutions present different combinations of the five different skills (table 2). In detail, IT professionals have high work performance, when they have entrepreneurial and communications skills, without having data analysis skills; regardless of business and communication skills (Solution 1). When business, communication and data analysis skills are absent, the IT professional can still has high work performance if one of the entrepreneurial or collaborative skills is present, regardless of the other (Solution 2 and 'solution 3). Further, solution 4 explains that an IT professional with entrepreneurial, business, communication and collaborative skills, has high work performance, regardless of his/her data analysis skills (Solution 4). Finally, when entrepreneurial, business, communication and collaborative skills are absent, the IT professional can still have high work performance, as long as the data analysis skills are present (Solution 5).

\section{Discussion}

Developing various skills for IT firms has gained enormous attention from executives, as noted by Luftman et al. [14] in the Society for Information Management. Rather than focusing on traditional soft and hard skills for general employees, we targeted IT professionals and examined factors related with the $21^{\text {st }}$ developments, like data-driven decisions and entrepreneurship amongst others. Unlike previous research which focused on skills as static characteristics of the employee, this study considers the stateof-the-art skills and their contribution to firms' competitiveness in a more dynamic and realistic manner.

The present study proposes that entrepreneurial, business, communication, collaborative and data analysis skills combine with each other to form configurations that ex- 
plain work performance of IT professionals. Building on complexity theory and configuration theory a conceptual model is created to identify such configurations. The model includes six constructs, that is the five types of skills and work performance. By employing the model to IT firms we collected data from 72 IT professionals and test the proposed model. The findings identify five solutions leading to high work performance, and showcase the significance of the five types of skills. The findings also indicate that there is an important interplay between the five types of skills and employees' work performance.

In detail, the five solutions present how an IT professional with a good set of these skills is productive (e.g. Solution 4 where four out of the five skills are present). In addition, the solutions indicate that IT professionals who are mastering few or even one of these skills, even with the absence of all the others (i.e. Solutions 2, 3 and 5), are able to overcome low disposition to some of the skills and be productive. Another important observation is the central role of today's data analysis skills, in solution 5 we can see that even with the absence of every other skill, data analysis skills can lead the professional to high work performance. This can be explained, by the fact that IT professionals with strong data analysis skills are the cornerstone for a company to move from competitive parity to competitive advantage [9]. In summary, the results show that the five types of skills are all important for IT professionals, and under different combinations can make IT professionals feel confident and productive (perceived work performance).

Based on related work and 21 st century technological developments, we selected to include a specific-range of skills and consider their influence on the personnel of IT firms. While we carefully selected those skills, the study might have been benefited from the inclusion of some more traditional skills (e.g., traditional hard and soft skills). Moreover, there may be other predicting factors other relationships between them might be discovered by using regressions techniques (e.g. SEM). Future research could establish other relationships by combining the proposed model with other potential predictors but also alternative data analysis approach; this can be addressed in a future large scale study.

Moreover, this study included only limited demographic variables (e.g., gender, experience) and due to the relative small sample size, we could not use them as configuration variables. Given prior research [15], individual characteristics, such as specific job-related skills, may result significant differences. In particular, employees who have higher levels of job-related skills will have a deeper understanding of the specific tasks [15]. Future research might also examine how these factors affect IT professionals' intention to learn new skills. A more detailed investigation of these skills and how these skills differ between specific department in an IT firm and their relation to firm's strategy, are also important directions for future research. Finally, the findings are based on self-reported data. Future studies may combine self-reported data with real data from firms' performance and strategy, as well as triangulate them with more qualitative data from interviews and observations. Although, this is pioneering study, and one of the first who attempted to explain the role of contemporary skills in IT firms. The collected data are from a limited number of IT professionals, from a specific country in a specific time. Thus, further research is needed, in a large scale context collecting longitudinal 
evidence, in order to enhance our current understanding of the relationships among different skills and their role in IT firms.

\section{References}

1. Boyles, T.: 21st century knowledge, skills, and abilities and entrepreneurial competencies: A model for undergraduate entrepreneurship education. Journal of Entrepreneurship Education, 2012, 15, 41 .

2. Byrd, T. A., \& Turner, D. E.: An exploratory examination of the relationship between flexible IT infrastructure and competitive advantage. Information \& Management, 39(1), 2001, 41-52.

3. Davenport, T.H., \& Patil, D. J... Data scientist: The sexiest job of the 21 st century. Harvard Business Review, 90 (10), 2012,70-76.

4. Finch, D. J., Peacock, M., Levallet, N., \& Foster, W.: A dynamic capabilities view of employability: Exploring the drivers of competitive advantage for university graduates. Education + Training, 58(1), 2016, 61-81.

5. Fiss, P.C.: 'Building better causal theories: A fuzzy set approach to typologies in organization research', Academy of Management Journal, 2011, 54, (2), pp. 393-420

6. Fornell, C., and Larcker, D.F.: 'Structural equation models with unobservable variables and measurement error: Algebra and statistics', J. Marketing Res., 1981, pp. 382-388

7. Gallagher, K.P., Kaiser, K.M., Simon, J.C., Beath, C.M., \& Goles, T.: The requisite variety of skills for IT professionals. Communications of the ACM, 53(6), 2010, 144-148.

8. Kim, G., Shin, B., Kim, K.K. and Lee, H.G.: IT capabilities, process-oriented dynamic capabilities, and firm financial performance. Journal of the AIS, 12(7), 2011, 487-51

9. Kiron, D., Prentice, P. K., \& Ferguson, R. B.: The analytics mandate. MIT Sloan management review, 55(4), 2014.

10. Lee, M.S., Trauth, E.M., \& Farwell, D.: Critical skills and knowledge requirements of IS professionals: A joint academic/industry investigation. MIS Quarterly, 19(3), 1995, 313-40.

11. Leftheriotis, I., \& Giannakos, M. N.: Using social media for work: Losing your time or improving your work?. Computers in Human Behavior, 31, 2014, 134-142.

12. Leitheiser, R. L.: MIS skills for the 1990s: A survey of MIS managers' perceptions. Journal of Management Information Systems, 9(1), 1992, 69-91.

13. Linan, F.: Skill and value perceptions: how do they affect entrepreneurial intentions?. International Entrepreneurship and Management Journal, 4(3), 2008, 257-272.

14. Luftman, J., Kempaiah, R., \& Henrique, E.: Key issues for IT executives 2008, MIS Quarterly Executive, 8(3), 2009, 151-159.

15. Morgeson, F. P., Delaney-Klinger, K., \& Hemingway, M. A.: The importance of job autonomy, cognitive ability, and job-related skill for predicting role breadth and job performance. Journal of Applied Psychology, 90(2), 2005, 399-406.

16. O'brien, R.M.: 'A caution regarding rules of thumb for variance inflation factors', Quality \& Quantity, 2007, 41, (5), pp. 673-690

17. Ordanini, A., Parasuraman, A., and Rubera, G.: 'When the recipe is more important than the ingredients a Qualitative Comparative Analysis (QCA) of service innovation configurations', Journal of Service Research, 2014, 17, (2), pp. 134-149

18. Pappas, I.O., Giannakos, M.N., and Sampson, D.G.: 'Making Sense of Learning Analytics with a Configurational Approach', in Editor (Ed.)^(Eds.): 'Book Making Sense of Learning Analytics with a Configurational Approach' (2016, edn.), pp.

19. Pappas, I.O., Giannakos, M.N., Jaccheri, L., and Sampson, D.G.: 'Assessing Student Behavior in Computer Science Education with an fsQCA Approach: The Role of Gains and Barriers', ACM Transactions on Computing Education (TOCE), 2017, 17, (2) 
20. Pappas, I.O., Kourouthanassis, P.E., Giannakos, M.N., and Chrissikopoulos, V.: 'Explaining online shopping behavior with fsQCA: The role of cognitive and affective perceptions', Journal of Business Research, 2016, 69, (2), pp. 794-803

21. Plewa, C., Ho, J., Conduit, J., and Karpen, I.O.: 'Reputation in higher education: A fuzzy set analysis of resource configurations', Journal of Business Research, 2016

22. Poston, R. S., \& Dhaliwal, J.: IS Human Capital: Assessing Gaps to Strengthen Skill and Competency Sourcing. Communications of the AIS, 36(1), 2015, 34.

23. Power, D. J.: Using 'Big Data' for analytics and decision support. Journal of Decision Systems, 23(2), 2014, 222-228.

24. Ragin, C.C., and Davey, S.: 'fs/QCA [Computer Programme], version 2.5', Irvine, CA: University of California, 2014

25. Ragin, C.C.: 'Fuzzy-set social science' (University of Chicago Press, 2000. 2000)

26. Ragin, C.C.: 'Redesigning social inquiry: Fuzzy sets and beyond' (Wiley Online Library, 2008. 2008)

27. Ragin, C.C.: 'Set relations in social research: Evaluating their consistency and coverage', Political Analysis, 2006, 14, (3), pp. 291-310

28. Rivera-Ibarra, J.G., Rodríguez-Jacobo, J., Serrano-Vargas, M.A.: Competency framework for software engineers. In Proceedings of the 23rd IEEE conference on software engineering education and training (CSEE\&T), 2010,33-40.

29. Sahami, M., Danyluk, A., Fincher, S., Fisher, K., et al.: Computer Science Curricula 2013: Curriculum Guidelines for Undergrad-uate Degree Programs in Computer Science. Association for Computing Machinery (ACM)-IEEE Computer Society, 2013.

30. Sambamurthy, V., Bharadwaj, A. and Grover, V.: Shaping agility through digital options: Re-conceptualizing the role of information technology in contemporary firms. MIS Quarterly, 27(2), 2003, 237-26

31. Topi, H., Valacich, J. S., Wright, R. T. et al.: Curriculum guidelines for undergraduate degree programs in information systems. ACM/AIS task force, 2010.

32. Wamba, S. F., Gunasekaran, A., Akter, S., et al.: Big data analytics and firm performance: Effects of dynamic capabilities. Journal of Business Research, 70, 2016, 356-365.

33. Wang, Eric T.G. Chiu, Chi-Hsing; and Chen, Kai-Xiang.: "Effect of IT Skills on IT Capabilities and IT-Business Alignment, In PACIS 2013 Proceedings. Paper 113, 2013.

34. Wang, Y. Y., Lin, T. C., \& Tsay, C.: Encouraging IS developers to learn business skills: an examination of the MARS model. IT \& People, 29(2), 2016, 381-418.

35. Wilson, K. E., Vyakarnam, S., Volkmann, C., et al.: Educating the next wave of entrepreneurs: Unlocking entrepreneurial capabilities to meet the global challenges of the 21st century. In World Economic Forum: A Report of the Global Education Initiative, 2009.

36. Woodside, A. G. (2014). "Embrace• perform• model: Complexity theory, contrarian case analysis, and multiple realities". Journal of Business Research, 67(12), 2495-2503.

37. Yu, P. L., Fang, S. C., \& Wang, Y. L.: Improving IT professionals job skills development: The use of management styles and individual cultural value orientation. Asia Pacific Management Review, 21(2), 2016, 63-73. 